Trinity University

Digital Commons @ Trinity

Psychology Faculty Research

Psychology Department

2000

The Cognitive-Initiative Account of Depression-Related

Impairments in Memory

Paula T. Hertel

Trinity University, phertel@trinity.edu

Follow this and additional works at: https://digitalcommons.trinity.edu/psych_faculty

Part of the Psychology Commons

Publication Details

The Psychology of Learning and Motivation

Repository Citation

Hertel, P. T. (2000). The cognitive-initiative account of depression-related impairments in memory. In D. L. Medin (Ed.), The psychology of learning and motivation (vol. 39, pp. 47-71). Academic Press.

This Contribution to Book is brought to you for free and open access by the Psychology Department at Digital Commons @ Trinity. It has been accepted for inclusion in Psychology Faculty Research by an authorized administrator of Digital Commons @ Trinity. For more information, please contact jcostanz@trinity.edu. 
Rovee-Collier, C., \& Sullivan, M. W. (1980). Organization of infant memory. Journal of Experimental Psychology: Human Learning and Memory, 6, 798-807.

Rovee-Collier, C., Sullivan, M. W., Enright, M. K., Lucas, D., \& Fagen, J. W. (1980). Reactivation of infant memory. Science, 208, 1159-1161.

Rozin, P. (1976). The psychobiological approach to human memory. In M. R. Rosenzweig \& E. L. Bennett (Eds.), Neural mechanisms of learning and memory (pp. 3-48). Cambridge, MA: MIT Press.

Rubin, G. B., Fagen, J. W., \& Carroll, M. (1999). Olfactory context and memory retrieval in 3-month-old infants. Infant Behavior and Development, 21, 641-658.

Schacter, D. L., \& Moscovitch, M. (1984). Infants, amnesics, and dissociable memory systems. In M. Moscovitch (Ed.), Advances in the study of communication and affect. Vol. 9: Infant memory (pp. 173-216). New York: Plenum.

Sherman, T. (1985). Categorization skills in infants. Child Development, 56, 1561-1573.

Shields, P. J., \& Rovee-Collier, C. (1992). Long-term memory for context-specific category information at 6 months. Child Development, 63, 175-214.

Spear, N. E., \& Parsons, P. J. (1976). Analysis of a reactivation treatment: Ontogenetic determinants of alleviated forgetting. In D. L. Medin, W. A. Roberts, \& R. T. Davis (Eds.), Processes of animal memory (pp. 135-165). Hillsdale, NJ: Erlbaum.

Strauss, M. S. (1979). Abstraction of prototypical information by adults and 10-month-old infants. Journal of Experimental Psychology: Human Learning and Memory, 5, 618-632. Squire, L. R. (1987). Memory and brain. New York: Oxford University Press.

Tulving, E. (1972). Episodic and semantic memory. In E. Tulving \& W. Donaldson (Eds.), Organization of memory (pp. 381-403). New York: Academic Press.

Tulving, E. (1983). Elements of episodic memory. New York: Oxford University Press.

Usher, I. A., \& Neisser, U. (1993). Childhood amnesia and the beginnings of memory for four early life events. Journal of Experimental Psychology: General, 122, 155-165.

Warrington, E. K., \& Weiskrantz, L. (1970). Amnesic syndrome: Consolidation or retrieval? Nature, 228, 629-630.

White, S. H., \& Pillemer, D. B. (1979). Childhood amnesia and the development of a socially accessible memory system. In J. F. Kihlstrom \& F. J. Evans (Eds.), Functional disorders of memory (pp. 29-74). Hillsdale, NJ: Erlbaum.

Wright, A. A., Santiago, H. C., Sands, S. F., Kendrick, D. F., \& Cook, R. G. (1985). Memory processing of serial lists by pigeons, monkeys, and people. Science, 22, 287-289.

Younger, B. A., \& Cohen, L. B. (1986). Developmental change in infants' perceptions of correlations among attributes. Child Development, 57, 803-815.

\section{THE COGNITIVE-INITIATIVE ACCOUNT OF DEPRESSION-RELATED IMPAIRMENTS IN MEMORY}

\author{
Paula T. Hertel
}

\section{Introduction}

The many and diverse interpretations of the word control make it clear that control constitutes a fundamental concern in most areas of psychology. In an illustration of this diversity, I described my interest in controlled uses of memory at a social gathering; my new acquaintances, without realizing the non sequitur, subsequently raised issues about self control and loss of control-issues much more relevant to their own interests in psychological phenomena than are my narrow musings. Yet a second thought devoted to the semantics of control reveals underlying commonalities. For example, when older people begin to have problems with controlled uses of memory, they sometimes feel like they are losing control in a more general sense.

Consider a related concept: initiative. When it is used in the context of research on memory and cognition, it refers to the research participants' use of cognitive procedures that are not specified fully by the constraints of the experimental task (e.g., Hertel \& Hardin, 1990). When it is used in an everyday context, however, it suggests an active motivational state or a certain readiness to perform, as in, "She showed excellent initiative in organizing the meeting." Yet, as the example illustrates, this everyday sense of initiative also sometimes includes the notion that procedures were accomplished without prior specification, that someone has done something 
they were not directly told to do. Turning the concept of initiative in the clinical direction, we easily observe that depressed people do not show much of it. The lack of initiative in the everyday sense is understood to be a fundamental characteristic of depression. Regardless of their readiness, however, people who are in depressed mood states often show deficits in initiative in the sense that refers to deficient cognitive control. They have difficulty initiating thoughts and actions, or at least the sorts of thoughts and actions that happen to produce benefits on routine cognitive tasks.

My interest in depression-related impairments in remembering was brought about by an accidental discovery that experimental control eliminated such impairments. When attention was well controlled by the demands of the task, and therefore did not have to be self-controlled, depressed participants recalled as well as did others. In this chapter, I review the lines of research that grew out of this accidental discovery and that my colleagues and I have called the cognitive-initiative framework. The reader should see that the sense of initiative that we have tried to capture since the late 1980 s or so refers to the unspecified or uninstructed use of procedures ("someone has done something they were not directly told to do"). However, this approach has occasionally been interpreted in a more broadly motivational sense. After reviewing some studies, both old and new, that illustrate the framework, the chapter discusses the broader interpretation and related approaches.

\section{The Framework and the Findings}

As a general approach for organizing findings of depression-related impairments in deliberate remembering, the cognitive-initiative framework makes three basic claims. First, evidence of impairments should be found under conditions in which attention is poorly controlled and cognitive procedures loosely constrained. Second, task structures and constraints that have been shown to benefit deliberate attempts to remember, when employed with participants in depressed and nondepressed states, should close the gap otherwise associated with the difference in state. In other words, the experimental control of attention-during initial exposure to the materials or during the memory test later on-should provide a good substitute for self-initiated control. Third, if the criterion task-the one that shows effects of prior experience-does not typically invoke deliberate remembering, depression-related impairments should not be found. In fact, on tasks that are actually disrupted by deliberate attempts to remember, depressed participants should fail to show the disruption. This section reviews research that supports each of these claims, beginning with the last as it plays out in the realm of problem solving.

\section{A. When Control DisRupts}

Like the memory literature, the literature on problem solving reveals difficulties associated with depressed mood states (see Williams, Watts, MacLeod, \& Mathews, 1997). According to most theoretical frameworks, these difficulties would be expected to emerge in some types of problemsolving tasks, particularly those tasks that require sustained attention to systematic steps in hypothesis testing. There is, however, a paradigm for studying spontaneous analogical transfer in problem solving that is procedurally similar to many memory paradigms and that has revealed an advantage to being in a depressed mood.

Spontaneous analogical transfer is typically studied by presenting logic and other kinds of word problems together with their solutions during a training phase. The training phase is followed by a transfer phase in which analogous problems are presented for solution without mention of the prior analogs. The paradigm, therefore, is procedurally similar to indirect tests of memory, during which no mention is made of the prior phase of initial exposure to materials. This parallel extends to the researchers' interests as well, because in both cases we are interested in revealing a benefit of prior "training" through its nondeliberate use. With this arrangement, Needham and Begg (1991) showed that spontaneous transfer profited from problemoriented training. In the problem-oriented condition, students were asked to try to solve each training problem before its solution was explained. Students in this condition accurately solved more transfer problems than did the students who had been given memory-oriented instructions during training-students who tried to learn the training problems and their solutions for a later test. (In a transfer-appropriate fashion, memory-oriented training produced superior recall of the training problems.)

One possible interpretation of the problem-solving results holds that the solutions to the training problems come to mind spontaneously as the students are introduced to the corresponding analogical problem structures, much in the same way that prior experience influences performance on indirect tests of memory. In other words, memory operates in a truly spontaneous or automatic fashion. Alternatively, problem solvers might notice similarities between the problem sets and initiate a deliberate and controlled search of memory for the appropriate solutions. In other words, memory might operate predominately in automatic versus controlled ways to facilitate the solutions to the transfer problems. Knowing the extent to which self-initiated, controlled reflection plays a role is important to the consideration of how well students in depressed or dysphoric ${ }^{1}$ moods should do.

${ }^{1}$ To avoid misrepresenting the state of depression, dysphoria is a term used to refer to naturally occurring negative affect, as it is measured by such instruments as the Beck Depression Inventory (Beck, Ward, Mendelson, Mock, \& Erbaugh, 1961) in the absence of clinical diagnosis through structured clinical interviews. 
Alicia Knoedler and I (Hertel \& Knoedler, 1996) predicted that performance of dysphoric students should be impaired if self-initiated reflection plays a significant role in the transfer phase. We also reasoned that if reflection plays a significant role, everyone (and especially the dysphoric students) should be helped by the provision of hints to think back to the analogous training problems before they try to solve the corresponding transfer problems. If memory is used deliberately and explicitly, cues should help. So in experiment 1, problem-oriented training was followed by a transfer phase with two conditions. Prior to each analogous transfer problem, half of the students-both dysphoric and nondysphoric-were given explicit hints to think of the appropriate training problems, whereas the other half were told merely to clear their minds and prepare for the next problem to solve.

Much to our surprise, the hints actually disrupted the performance of the nondysphoric students, compared to the no-hint controls. After replicating this finding, we began to see it as an example of transfer-appropriate processing (Morris, Bransford, \& Franks, 1977). Problem-oriented training encouraged an initial focus on the structure of the problem; this focus had more in common with the focus in the no-hint condition of the transfer phase than it did with the focus in the hint condition. Instructions in the hint condition focused attention on the past, and perhaps on details of the problems in place of the more abstract relations among their elements. Regardless of the reason, the fact that the hints actually hindered performance by nondysphoric problem-solvers argued against self-initiated reflection as the primary way transfer was achieved in the no-hint condition. Knoedler and I (1996) concluded that spontaneous transfer in the no-hint condition was more likely achieved by the spontaneous use of memory than by a self-initiated and deliberate search; the method of solution came to mind as the analogous structure was conceived.

On this view, we would not expect to find a depression-related impairment in the no-hint groups, and we did not. More surprising (again, and replicated) was the finding of a reliable advantage to feeling depressed when hints were provided. Figure 1 reproduces the mean percentage of problems solved by dysphoric and nondysphoric participants in both conditions of experiment 1 . It is apparent that the dysphoric participants solved reliably more problems than the nondysphoric participants when everyone was given hints; Knoedler and I surmised that the dysphoric participants did not follow instructions to think back and thereby avoided the corresponding pitfalls. Now, cases in which controlled reflection disrupts performance are probably rare, particularly in the memory investigations that experimentalists tend to emphasize. We do like to imagine situations in which past experience is more beneficial if one "goes with the flow" in place of being

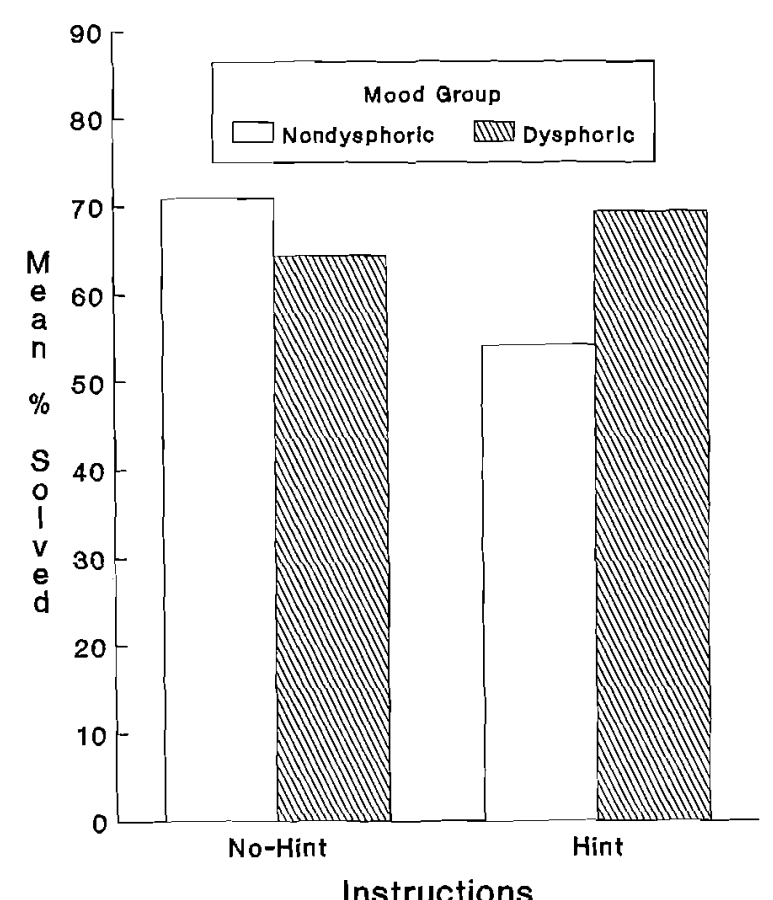

Fig. 1. The mean percentage of transfer problems solved by dysphoric and nondysphoric students who were either given hints to remember the training analogs or told to clear their minds in the no-hint condition. From a table in "Solving Problems by Analogy: The Benefits and Detriments of Hints and Depressed Moods," by P. T. Hertel and A. J. Knoedler, 1996, Memory \& Cognition, 107, p. 19. Copyright (C) 1996 by the Psychonomics Society; adapted with permission of the authors.

more reflective, and in those cases a depressed mood could help us avoid the pitfalls of searching our memory in vain. Much more common is the situation in which memory operates spontaneously and sometimes without awareness. No one tells us to reflect back and no one thinks to do so.

\section{B. When Control Is Beside the Point}

Successful indirect tests of memory put nondepressed participants on the same footing with depressed participants, because neither group shows initiative in controlled uses of memory. Indirect tests are carefully designed to insure that participants do not deliberately think back to a prior experimental phase as they are spelling homophones, completing word fragments or word stems, or freely associating to cues. Indeed, no differences have been found on tests of homophone spelling (Hertel \& Hardin, 1990), word 
completion (Danion et al., 1991; Denny \& Hunt, 1992; Watkins, Mathews, Williamson, \& Fuller, 1992), or free association (Watkins, Vache, Verney, Muller, \& Mathews, 1996). Yet the extent to which a particular word comes to mind to provide a spelling, complete a stem, or relate to a cue should also reflect the extent to which that particular word was attended initially. The results of one experiment that revealed differences associated with depression perhaps did so because the words were poorly attended in the first place (Hertel, 1994).

In that experiment, performed with clinically depressed and nondepressed participants from the community, two types of rating tasks were used in phase 1 . In one block the words were rated for their emotional value, and in the other block they were rated for the degree of curvature in their perceptual form. These rating blocks were followed by a test of perceptual identification, in which new words and previously rated words were presented very briefly and back-masked; the task was to read the words aloud. As anticipated, words previously rated for their emotional value were identified more readily than were new words, regardless of the mood group. However, the effect of prior exposure in the curvature task was reliably smaller in the depressed group than in the nondepressed group. Blocking according to the type of rating might have been the key to producing this depression-related impairment, because a block of curvature ratings could be completed without even noticing what the letters spelled. In other words, some of these words might have been read by depressed participants for the first time on the test. The focus of attention matters, if merely to establish a perceptual record of having read a word. The larger principle illustrated by this isolated finding is that procedures across episodes should be transfer appropriate if the past is to benefit the present.

\section{When Control Is Beneficial}

Impaired performance on tests of intentional or deliberate memory typically occurs when attention is poorly controlled by external means. The extreme "proof" of this claim is the simple demonstration in which a neurologically healthy person is constrained to attend to nothing else except the material at hand, and then the material is swept away and an instant later the request for memory is posed. To the extent that variations in attention are introduced-perhaps in the form of a retention interval in which this person must attend to other things or perhaps through the introduction of other materials that vie for attention-performance on the memory test suffers. Performance always relies on the ability of the rememberer to direct attention to events that are no longer occurring-events in the past. And performance always benefits from the transfer-appropriate use of attention during initial exposure, which is rarely well arranged, either naturally or experimentally. Therefore, variations in performance on tests of deliberate remembering are correlated with the extent to which the rememberer initiates beneficial procedures without being constrained to do so by the demands of the task. Initiative is important in an unplanned world.

\section{On Tests of Free Recall}

Stephanie Rude and I accidentally discovered that initiative is important to the understanding of memory in depressed states when we tried to replicate some results obtained by Ellis, Thomas, and Rodriguez (1984). Ellis et al. experimentally induced sad or neutral moods, and then presented the students with a semantic orienting task followed by a surprise test of free recall. The orienting task was to judge whether a target word fit meaningfully in a corresponding sentence frame. The frames established more or less difficult or distinctive contexts for the words to be recalled; distinctiveness benefited target recall by participants in a neutral mood, but not by those in a sad mood. Another way of looking at the results revealed that the students in a sad mood recalled fewer words from the more distinctive contexts than did the students in a neutral mood. In a prior study (Tyler, Hertel, McCallum, \& Ellis, 1979), the more distinctive frames, compared to the less distinctive ones, had also produced longer latencies on a secondary task intended to measure cognitive effort, or the amount of attentional resources expended in judging whether the words fit into the frames. Therefore, Ellis et al. concluded that the students induced to feel sad had insufficient resources available to encode the target words in those frames. They also generalized these results to depressed people, and Rude thought the justification for this generalization was worth investigating. Judging the fit of words like "artist" in sentences such as "The young man's physique was admired by the " did not seem too effortful for even a depressed person to do.

Our first study (Hertel \& Rude, 1991b, experiment 1; Rude \& Hertel, 1987) revealed quite the opposite pattern to what Ellis et al. found. Naturally dysphoric students actually recalled more words from both types of frames than did the students who were not dysphoric. Although we speculated about why they performed better (why the finding might have been real instead of a type-I error), the more important point was that they did not perform worse than the nondysphoric participants. This result led us to consider the methodological differences between the two experiments, other than the nature of participants' moods. The main differences were that Rude and I had required participants to repeat the target word at the end of each trial and then report whether it fit the frame, whereas Ellis et 
al. (1984) did not require repetition and had accepted the judgment of fit at any point during the trial. These differences were incorporated into the design of subsequent experiments, as was the variation in the type of mood (naturally occurring versus experimentally induced). We replicated the recall deficit found by Ellis et al. when we used their method and eliminated it when we used our own. Later, we extended our findings to clinically depressed outpatients, nondepressed outpatients, and outpatients recovered from depressive episodes (Hertel \& Rude, 1991a). The mean percentages of words recalled from the more distinctive frames are shown in Fig. 2. The figure illustrates the point that depressed people have sufficient "resources" to attend in ways that benefit subsequent recall. What matters is how that attention is controlled. The focused condition of initial exposure required participants to keep each word in mind for the duration of the 8 -s trial in order to repeat it; this procedure also might have encouraged additional attention to the contextual frame and a more distinctive record for retrieval. The unfocused condition permitted such episodic enrichment, but at the behest of self-sustained attention. It was possible to think about other matters or not think at all. In short, there was room for initiative in the focus of attention. Again, the focus of attention matters, this time to establish a richer basis for deliberate retrieval.

\section{On Tests of Recognition}

So far, it seems that tests that require deliberate retrieval are most sensitive to prior variations in cognitive initiative and corresponding depressionrelated impairments, whereas tests that do not-indirect or implicit testsare least sensitive. One might imagine that recognition tests fall somewhere in the middle, given that they typically invoke a mixture of controlled and automatic retrieval processes (see Jacoby, 1991). Controlled judgments of prior occurrence can be based on a deliberate consideration of the prior context of the test items. Automatic influences can also guide recognition judgments; items are perceived or conceived more fluently the second time around (on the test), and that fluency is experienced as familiarity (see Jacoby, Kelly, \& Dywan, 1989). Most likely, both controlled and automatic uses of the past are invoked on most recognition tests. However, probably because recognition tests can be performed by relying on more automatic processes, depression-related impairments are rarely observed. Therefore, to reveal possible impairments in the controlled component alone, Stephanie Milan and I used Jacoby's (1991) process-dissociation procedure for recognition (Hertel \& Milan, 1994).

We presented essentially unrelated pairs of words during phase 1 and asked dysphoric and nondysphoric students to judge their relatedness. In

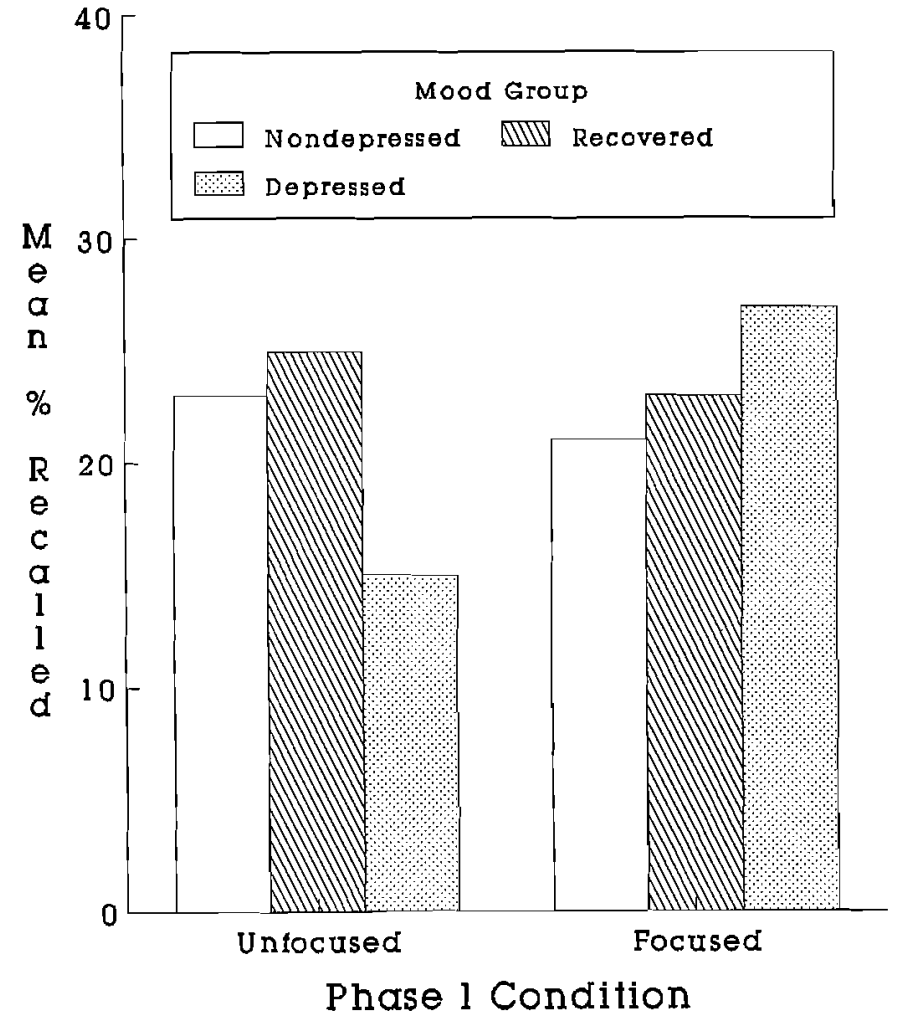

Fig. 2. The mean percentage of words recalled from the more distinctive sentence frames presented in phase 1. Participants were clinically depressed, recovered from episodes of depression, or nondepressed controls. Their attention to the experimental materials in phase 1 was either unfocused or focused by the demands of the task. From a table in "Depressive Deficits in Memory: Focusing Attention Improves Subsequent Recall," by P. T. Hertel and S. S. Rude, 1991, Journal of Experimental Psychology: General, 120, p. 304. Copyright (C) 1991 by the American Psychological Association and adapted with permission of the authors.

phase 2 , they listened to single words on audio tape and tried to remember them for a later test. Then the recognition test was performed on the first members of the pairs in phase 1 , the single words from phase 2 , and words not previously presented. On half the trials (inclusion) the participants were instructed to call the words old regardless of whether they thought they had occurred in phase 1 or 2 ; they could make this judgment either on the basis of controlled recollection or on familiarity in the absence of control. On the other half (exclusion), they were instructed to call only 
words from phase 2 old; phase- 1 words should be excluded. By assuming that the two bases of recognition judgments were independent, ${ }^{2}$ we computed estimates of each component and used those estimates as the dependent variables in separate analyses. The estimates of the controlled, recollective component of recognition memory were reliably lower in the dysphoric group than in the nondysphoric group, but the estimates of the automatic component of familiarity were similar.

Unlike the situation with free recall, in which participants have little recourse when they cannot reflectively attend (other than to guess, of course), old/new recognition decisions can be made without going to a lot of trouble to think back. By using a process-dissociation procedure, however, Milan and I were able to show that the flexibility in how recognition is performed allowed room for initiative in cognitive control. (Exclusion instructions can be taken with a grain of salt if one finds it difficult to conjure up prior contexts.) We also thought that if we could constrain attention better in this testing situation, we might be able to close the dysphoriarelated gap in the estimates of control. Therefore, in another condition of the test, pairs of words were presented. These pairs were presented intact from phase 1 , or they were phase- 2 words paired with new words, or they were pairs of entirely new words. We instructed participants in the paired condition that the second member of the pair could help them make the recognition decision. In effect, we were giving them a basis for source monitoring on exclusion trials, becuase if the second member of the pair also seemed old they could be more certain that the first member of the pair came from phase 1 and should be excluded.

The contextual support helped, of course. Compared to the single-item test, the paired test raised estimates of the automatic component for everyone; greater fluency from the replicated partners made the target words feel more familiar. The paired test also provided everyone with a better basis of controlled reflection, dysphoric and nondysphoric participants alike. Thus, we failed to even partly alleviate the dysphoric participants' deficiency in controlled recollection. One possible reason was that the sourcemonitoring stratey was not guided on a trial-by-trial basis. Another possible reason was that $6 \mathrm{~s}$ were allotted for each relatedness judgment in phase

2 Jacoby's equation to represent the probability of (correctly) endorsing a phase-1 word on inclusion trials captures the assumption of independent controlled and automatic processes: $P\left(\right.$ old $\left._{\text {inclusion }}\right)=C+(1-C) A$, where $C$ equals the probability of controlled recollection and $A$ equals the probability of automatic influences. The equation to represent the probability of (erroneously) endorsing a phase-1 word on exclusion trials is: $P\left(\right.$ old $\left._{\text {exclusion }}\right)=(1-C) A$. By subtracting the second equation from the first-in practice, by subtracting the proportion of erroneously endorsed phase- 1 words during exclusion from the proportion of correctly endorsed phase-1 words during inclusion-estimates of controlled recollection are obtained for each participant.
1 -enough time to produce variation in attention during initial exposure to the pairs and consequently variable bases for controlled reflection.

In a much earlier series of recognition experiments that relied on source monitoring in a different way, Tammy Hardin and I were more successful in closing the dysphoria gap (Hertel \& Hardin, 1990). We obtained stochastic independence between performance on an indirect test of homophone spelling and performance on a subsequent recognition test, but only when participants were dysphoric. The nondysphoric students' responses on the two tests were correlated. They seemed to use the strategy of checking memory for how they had spelled the word on the indirect test and then asked themselves if that word (e.g., "pear" instead of "pair") had been presented in the first phase. (The first phase posed questions such as, "What color is a pear?") We led all participants through the steps of that strategy on each trial in a subsequent experiment. The dsyphoric participants showed stochastic dependence, just as the others had done without guidance, and the previously obtained deficit in ( $d$-prime) recognition scores was now not found.

These early experiments with Hardin provided a good set of examples of how low initiative on the part of dysphoric or depressed people could be compensated for by successful experimental control of attention. In an ongoing series of recognition experiments, Colleen Parks and I have been trying a different tack-one that seeks to take advantage of the tendency to attend to mood-congruent events.

\section{On Tests of Recognizing Emotional Material}

For people who are in depressed or dsyphoric states, mood-congruent memory is a fairly robust phenomenon (for reviews, see Gotlib, Roberts, \& Gilboa, 1996; Williams et al., 1997). Depressed participants produce superior recall for negative trait adjectives, for example, compared to their own recall of positive trait adjectives and sometimes compared to nondepressed recall of negative adjectives. Clearly in these paradigms, depression is not associated with problems in initiating or sustaining attention to moodcongruent materials. Parks and I are attempting to use this attentional tendency as a focusing device by providing emotional contexts for the neutral materials to be remembered later. If this method is successful, in the long run it will offer the extra advantage of solving a problem inherent in mood-congruent research designs.

One of the methodological sticky points encountered by mood-congruent experiments has been the "materials" problem. These experiments typically are built around emotionally valenced nouns or adjectives. However, no matter how carefully one tries to balance positive and negative word lists 
according to characteristics like concreteness, meaningfulness, and frequency, other differences between the lists cannot be ruled out. Researchers have often suspected that negatively toned words are better interrelated, for example. To address this problem, we have been trying to make neutral words emotional by manipulating how they are experienced during initial exposure. Nouns were selected for their emotional neutrality and then paired with adjectives such that each noun could be presented as an emotionally positive or negative pair (e.g., "flawless skin" or "slashed skin"; "warm cottage" or "gloomy cottage"). Lists were balanced on a number of dimensions, including pilot ratings for the emotional values of all pairs, and counterbalanced with the levels of the within-subjects factors in the design. Equal numbers of participants in each mood group experienced "skin" (for example) in a positive sense, in a negative sense, as a single word in a separate study phase, and as a new word on the recognition test.

In one of these experiments, we told the students that they were participating in a memory experiment, but before it was to begin, we needed some ratings for materials to be used in future experiments. That was our cover story for phase 1 , and it provided the rationale for exclusion instructions on the test. During phase 1, 30 word pairs (in blocks of 5 positive or 5 negative) were presented for $6 \mathrm{~s}$ each, and the participants were instructed to generate an image of themselves interacting with the event the pair described. The pair's presentation was followed by a rating scale, which they used to rate the emotional value of the image. The rating was selfpaced. Thus, we believed that we gave participants ample opportunity to devote as much or as little attention to the pairs as they chose to do.

The rating task was followed by the so-called memory experiment. In phase 2, 30 single nouns were presented for $1.5 \mathrm{~s}$ each. (Fifteen of those were "critical" nouns, from a list that was rotated through all conditions as part of the counterbalancing procedures.) Instructions for the "yes/no" recognition test alerted subjects about the need to exclude words from the rating task and endorse as recognized only those words they studied in the preceding phase. The test consisted of 90 trials: 15 nouns from positive pairs in phase 1,15 from negative pairs in phase 1,15 critical phase- 2 nouns, 15 critical new nouns, 15 phase- 2 fillers, and 15 new fillers. (Fillers were similar to the other nouns but were not rotated through all the conditions.) On each test trial, a single noun was presented for $2000 \mathrm{~ms}$, and during the last $750 \mathrm{~ms}$ it was accompanied by a row of asterisks underneath. The participants understood that they should not press the $\mathrm{Y}$ or $\mathrm{N}$ key until the asterisks appeared, and they were given 15 practice trials to become accustomed to this procedure. After the main test, the participants filled out a Beck Depression Inventory (BDI). They had been preselected according to scores on a classroom administration of that inventory, and only the data from those participants whose scores remained in the same categories were analyzed. ${ }^{3}$

Parks and I predicted that $2 \mathrm{~s}$ would be ample time to recruit the prior context and exclude the nouns from well-attended trials during phase I. If the dysphoric students had sustained attention and constructed distinctive images on the negative trials in particular, those nouns should have been more successfully excluded than nouns from the positive trials and as successfully excluded as were negative nouns by nondysphoric students. The mean percentages of yes responses are presented in Fig. 3.

We first performed an analysis of variance (ANOVA) on the number of yes responses from the so-called memory experiment. Mood group (dysphoric versus nondysphoric) constituted the between-subjects factor and item type (phase-2 versus new critical nouns) the within-subjects factor. The main effect of item type was obviously reliable $[F(1,30)=213.3$, $M S E=4.80, p<.001]$. Both the interaction with mood and its main effect were not reliable $(F \mathrm{~s}<1.0)$.

Next we evaluated differences in the number of exclusion errors (the number of yes responses) according to mood group and valence of the phase- 1 material. Dysphoric participants made more errors overall $[F(1,30)=8.58, M S E=7.46, p<.01]$. This difference seemed greater for positive trials than for negative ones, although the interaction with valence was not reliable $[F(1,30)=2.38, M S E=3.18, p>.10]$. Yet, the difference between mood groups in excluding nouns from negative trials was not reliable at the .05 level of significance, particularly when the baseline difference was used as a covariate. In short, we have been somewhat successful in closing the dysphoria-related gap in memory for neutral materials by capitalizing on mood-congruent interests. This line of research continues.

One other aspect to these results deserves mention: The absolute value of the difference in exclusion errors made to nouns from positive versus negative contexts was 1.1 on average in the nondysphoric condition, but 3.0 in the dysphoric group $[t(30)=4.20, S E=0.45, p<.001]$. The manipulation of valence clearly had a larger effect for the dysphoric students, if not always the same sort of effect; 10 participants made fewer exclusion errors on negative nouns, but 6 participants made fewer errors on positive nouns. Mood-incongruent memory would be produced if those students attempted mood repair by attending more carefully on the positive trials (see Gotlib et al., 1996).

${ }^{3}$ Participants were selected initially if they scored below 6 or above 9 on the BDI. The data from 7 participants were set aside and replaced, because the end-of-session scores did not fall in the same category. The data from 8 additional participants were replaced due to a variety of running errors (insufficient fluency in English, misunderstood instructions, interruptions by maintenance workers). Finally, the data from 16 participants in each mood group were analyzed; they were equally distributed across the four counterbalancing conditions. 


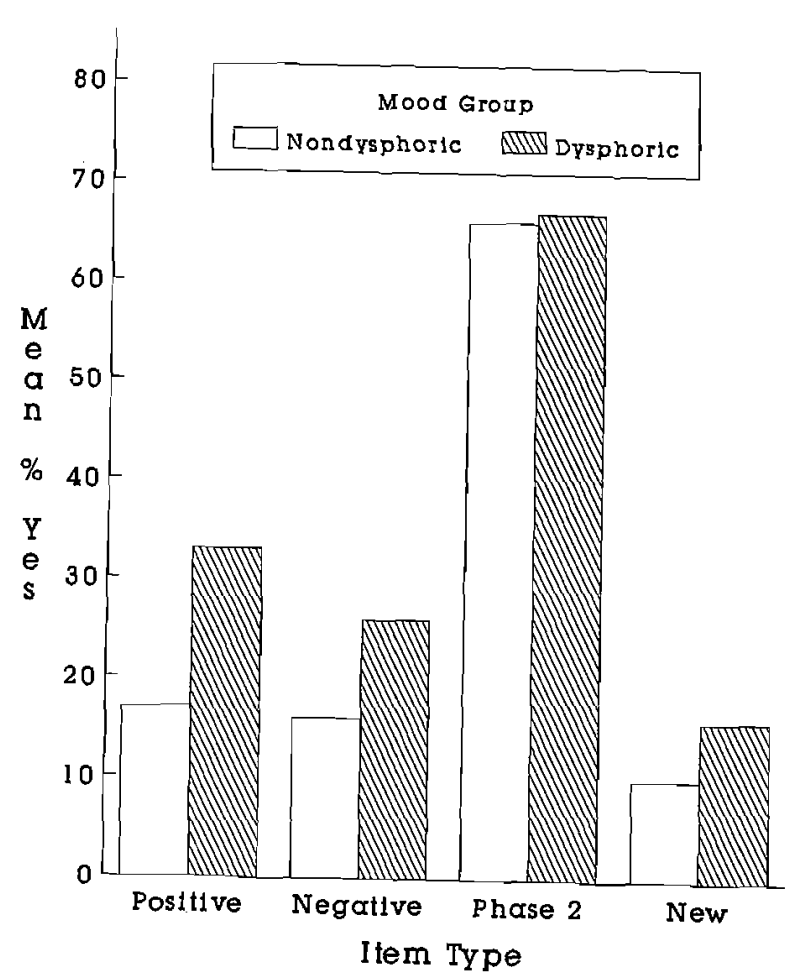

Fig. 3. The mean percentage of words endorsed as studied by dysphoric and nondysphoric students. The words were made positive or negative by a phase- 1 task, studied in phase 2 , or newly presented on the test. "Yes" responses were appropriate only for phase-2 words (Hertel and Parks, in progress).

\section{On Tests of Prospective Memory}

With sufficient initiative or assistance from others, depressed people seek out psychotherapists to help with mood-repair efforts. Among the complaints presented to psychotherapists are difficulties with memory. What do people mean when they say they have trouble with memory? Certainly they do not mean that memory is failing them in spontaneous or automatic ways. If we are not aware that memory is operating-on those ubiquitous indirect tests of everyday life-we do not think to complaint about trouble with memory. Moreover, as discussed in an earlier section, depressed people's memories are probably not failing them in this respect.

Sometimes when people complain about their memory they mean that they forget names. (Memory researchers are often asked for hints about how to remember names, probably because forgetting names can be embarassing.) More likely, however, people mean that they forget to do things, because forgetting to do things can have important consequences. The field of prospective memory is the study of memory for carrying out intentions in the future, and it is an obvious domain for investigations of depressionrelated deficits in self-initiated uses of memory.

Einstein and McDaniel (e.g., 1990) conducted a number of experiments on prospective memory and aging. A useful distinction established by their work is the one between time-based and event-based prospective tasks. Event-based tasks essentially provide cues for carrying out the intention (the pill container placed by the coffee pot), whereas in time-based tasks the passage of time is the signal for the act (of taking a pill every 4 hours, for example). In particular, Einstein and McDaniel's older participants have shown impaired prospective memory on time-based tasks, which require more self-initiation than do event-based tasks.

Depressed people have a lot in common cognitively with older people, who are also impaired in controlled uses of memory for past events (e.g., Jennings \& Jacoby, 1993). Stephanie Rude and I anticipated that the similarity would be found in this prospective domain as well (see Rude, Hertel, Jarrold, Covich, \& Hedlund, 1999). We recruited clinically depressed and nondepressed volunteers from the community and used procedures similar to those used by Einstein and McDaniel in their time-based condition. The participants were instructed to press the $\mathrm{F} 1$ key on the computer keyboard every $5 \mathrm{~min}$ while they were answering general-knowledge questions (a 30-min task), and they could access a digital clock by pressing another key. We found a depression-related impairment in the number of prospective responses and also in the number of times the clock was checked. As seen in Fig. 4, time monitoring increased in frequency toward the end of the 5-min interval to a greater extent for the nondepressed participants than for the depressed. (The dropoff in the fifth segment of the interval reflects the fact that the prospective response itself could be made at the end of that interval.) These results are quite compatible with an initiative account of depression-related or age-related deficits, as well as with other accounts that stress deficient control. The next step is to try to remediate this impairment by introducing a focusing manipulation. In the meantime, let's consider why such a manipulation might work by examining the possible reasons for poor initiation in depressed states.

\section{The Role of Motivation in Memory Impairments}

The cognitive-initiative account of memory impairments is a general cognitive framework. By that I mean that it should apply to any situation or 


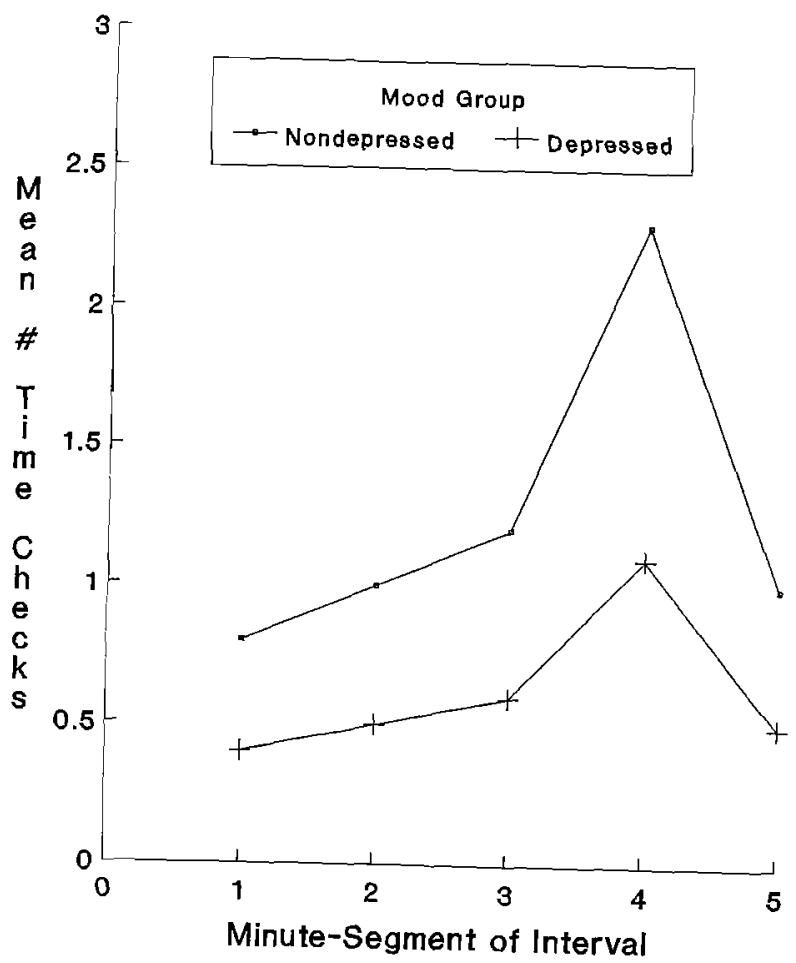

Fig. 4. The mean number of times the clock was checked in each minute prior to the time for the prospective response. Means were computed across participants in each mood condition and across the six opportunities for the prospective response. (From a table in "Depressio related impairments in prospective memory," by S. S. Rude, P. T Hertel W Depression Covich, \& S. Hedlund, 1999, Cognition \& Emotic Press Ltd.) reprinted by permission of Psychology Press

state that would occasion poor self-initiated processing, not just depressed mood. In fact, the notion of reduced initiative has been used by Craik (1986) to address age-related memory impairments. A separate issue is the question of why the account should apply to depressed people in the first place. As is suggested by the everday meaning of initiative, perhaps these difficulties are motivational in nature (see Abramson, Metalsky, \& Alloy, 1989). Indeed, researchers have sometimes referred to the initiative framework as a motivational account (e.g., Hartlage, Alloy, Vazquez, \& Dykman, 1993). Consider this description by Ellis, Ottoway, Varner, Becker, and Moore (1997, p. 132): "Individuals in a disruptive mood state may simply be less motivated or energized to perform well in demanding tasks, that is, they may lack sufficient initiative to perform the task adequately (e.g.,
Hertel \& Rude)." Plainly, the word initiative has been taken to mean either incentive or arousal, although we have never described memory impairments in those ways. However, the cognitive-initiative account can be conceptualized as motivational in two other ways.

As is sometimes suspected with aging, the difficulty in self-initiation is potentially related to reduced activation in the frontal regions of the cortex (e.g., Henriques \& Davidson, 1991), the areas understood as responsible for planning, monitoring, initiating, and sustaining attention. The extent of this neuropsychological basis for reduced initiative should vary with the severity of the depression (Johnson \& Magaro, 1987). Furthermore, on neuropsychological grounds, reduced initiative in the control of attention might underlie depression-related difficulties in other goal-directed behaviors, in addition to those related to remembering. The commonalities among the different meanings of the terms control and initiative, mentioned at the beginning of the chapter, can probably be attributed to their frontal roots. In that fundamental sense, the cognitive-initiative account does seem to be a motivational account of memory difficulties.

Another motivational aspect of the initiative framework is quite different. Consider Simon's (1994) description of the relations among attention, memory, and emotion: "Items in memory with which emotion is associated are, ceteris paribus, more easily aroused than other items and hence more capable of directing attention or causing interruption of attention. They operate much like motives but are associated with perhaps less specific goals than motives usually are" (p. 19). In this sense, most approaches to depression and memory (e.g., Ellis \& Ashbrook, 1988; Williams et al., 1997) are motivational. They generally assume that depressed people are motivated to attend to personal concerns-"to items in memory with which emotion is associated." Task materials that are related to those concerns are attended and remembered, thereby producing mood-congruent memory, and those that are unrelated suffer from neglect while personal concerns preempt attention. Like these other views, the initiative account is a motivational account in that it acknowledges that personal concerns and interests can divert attention that would otherwise be focused on the task at hand. Is there reason to believe that such diversions underlie impaired memory for neutral events? I conducted an experiment that addresses this question (Hertel, 1998).

This experiment had three phases: The first and last were close replications of the materials and procedures used by Jacoby (1996). Word pairs (e.g., "building stone") were presented at a 2-s rate, and the participants read them aloud in anticipation of a later memory test. The form of the test was fragment completion on the second member of the pairs from phase 1 (e.g., "building _to _e e"), conducted according to process-dissociation 
procedures. On half of the trials, inclusion instructions were given. The participants were told that they should complete the fragment with a word from phase 1 that was related to the context word ("building") or, if they could not remember such a word, they should complete the fragment with the first word that comes to mind that is related to the context word. On exclusion trials they were told to try to remember a word from phase 1 that completes the fragment but not to use that word; instead they should use another word that fits the fragment and is related to the context word (e.g., "store"). By assuming that controlled and automatic uses of memory operate independently in this paradigm, we calculated estimates of each component. What we were most interested in were the estimates of the controlled component. Recall that we had previously shown dysphoriarelated impairments in controlled reflection within a recognition paradigm (Hertel \& Milan, 1994). I hoped to replicate this effect and, moreover, gain some insight about why it might occur. To do that, I used three versions of a second phase of the experiment, interspersed between the study and test phases.

In the unconstrained version of phase 2 , the experimenter fiddled with the computer and shuffled papers for $7 \mathrm{~min}$, while the participants sat quietly and did nothing. At least they did nothing that the experimenters could observe; certainly, they were entitled to their thoughts. The point of using such a long interval was to invite the dysphoric participants to entertain the kind of thoughts that are often blamed for poor performance in laboratory memory tasks: automatic negative thoughts that Beck and others documented in the clinical literature (see Beck, Rush, Shaw, \& Emory, 1979; Williams et al., 1997). Clearly, prior practice in entertaining these concerns during "free times" causes them to come to mind automatically during future unconstrained periods. Practice in attending makes the attended thought automatic (see Logan \& Etherton, 1994). Once personal concerns come to mind, it should be difficult to dismiss them and control one's attention to the past during the memory test. The thoughts are simply more compelling or attention demanding than are the mundane events of the experiment. A difficulty for the researcher, however, is to determine if indeed these kinds of thoughts occur. If you ask the participants during the interval, you encourage the thoughts, and if you wait until later, you rely on memory and establish demand characteristics associated with the timing of the request (see Hertel, 1997; Parrott \& Hertel, 1999). For these reasons, I chose to use two other conditions of the experiment as alternative models for what might have happened in the unconstrained condition.

Only three kinds of cognitive activities were possible during the $7 \mathrm{~min}$. The participants could have entertained no thoughts at all, self-focused thoughts, or other-focused thoughts. (Admittedly, various combinations were also possible.) I eschewed the condition of no thoughts at all, because it seemed like an impossible outcome to pull off experimentally. To encourage self-focused or neutral (other-focused) thoughts, I slightly modified phrases borrowed from Nolen-Hoeksema and Morrow (1993). Their neutral phrases refer to geographic locations and objects (e.g., "the shape of the continent of Africa"). Although their self-focused phrases (e.g., "my character and who I strive to be") are not inherently negative, they have been shown to encourage ruminative thoughts in depressed and dysphoric participants.

In each of the separate phase-2 conditions-self-focused and neutraldysphoric and nondysphoric participants were instructed to read each phrase, form an idea of the meaning of the phrase, and then rate the clarity of that idea. They performed this rating task for $7 \mathrm{~min}$. If the self-focused phrases encouraged rumination in the dysphoric group, I expected to see a corresponding impairment on estimates of the controlled component of memory on the subsequent test. The neutral condition was an important control for the nature of the thoughts. Frontal hypoactivation or some other cause of generalized distractibility might make it difficult to focus attention on the past. After all, it was possible to perform the test by relying on more automatic influences of memory.

Figure 5 shows the mean estimates of control in this experiment. The impairment in the unconstrained condition was reliable. It was mimicked by the pattern obtained from participants in the self-focused condition, and the difference was eliminated in the condition in which the participants thought about other matters. A very similar pattern also obtained when these data were reanalyzed by using the extended measurement model of Buchner, Erdfelder, and Vaterrodt-Plünnecke (1995; see Hertel \& Meiser, in press). For dysphoric students, then, the self-focused condition provided a good model for the deficit obtained in the unconstrained condition. Of course, we cannot be sure of this interpretation, given the fact that the same pattern could be produced by different processes. However, we do know that a simple mood-change account probably is not sufficient. Mood ratings at the end of the test were no more extreme in the self-focused condition than in the neutral condition (nor were the scores on the BDI). It is also important to realize that more fundamental motivational difficulties might characterize the impairments of clinically depressed patientsperhaps the sort that are associated with frontal hypoactivation. These issues merit further research, perhaps more creatively conceived, aimed at the understanding of the processes responsible for poor initiation and control in depressed and dysphoric moods.

\section{Comparisons and Conclusions}

In addition to a shared motivational flavor, the cognitive-initiative approach is compatible in other respects with earlier conceptualizations of 


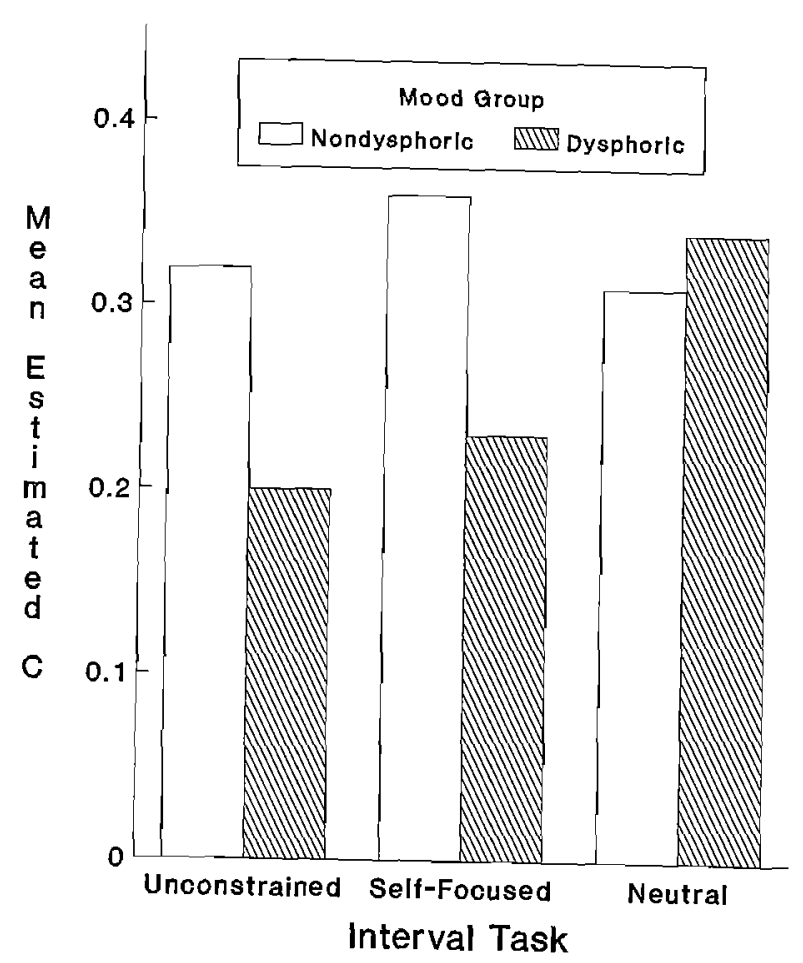

Fig. 5. The mean estimate of the controlled component of memory in a fragmentcompletion test, following an unconstrained interval, a self-focused rating task, or a neutral rating task. Adapted from "The Relationship between Rumination and Impaired Memory in Dysphoric Moods," by P. T. Hertel, 1998, Journal of Abnormal Psychology, 107, p. 170. Copyright (C) 1998 by the American Psychological Association.

depression-related impairments (e.g., Ellis \& Ashbrook, 1988; Hasher \& Zacks, 1979; Weingartner, Cohen, Murphy, Martello, \& Gerdt, 1981; Williams et al., 1988). In the main, these earlier approaches employed spatial metaphors and put forward the notion that competing thoughts occupy capacity or tie up resources that the depressed or dysphoric person might otherwise use to perform a cognitively demanding task. In contrast, my collaborators and I employed procedural metaphors and argued that capacity metaphors are not sufficient to explain the entire pattern of depressionrelated performance.

Essentially, there are three types of phenomena that are difficult to explain by using a capacity-based metaphor alone. First, in the experiment just described, the elimination of the opportunity to ruminate also eliminated the impairment in controlled use of memory (Hertel, 1998); capacity accounts rarely permit this degree of flexibility. Second, a deficit has been found on the simple task of perceptual identification (Hertel, 1994), and the condition of initial exposure that produced the deficit was the less resource-demanding task: the task of rating curvature, not the task of rating emotionality. Third is evidence that external control can sometimes compensate for deficiencies in less-structured situations, even when the task is resource-intensive (Hertel \& Hardin, 1990; Hertel \& Rude, 1991a,b). Thus, the contribution of the initiative framework has been to emphasize the importance of attentional control during unstructured conditions. It is important to know whether such control is disruptive, irrelevant, or beneficial to performance on the memory task. When it is beneficial, external mean can be used to focus attention appropriately. Whether guidance remediates depression-related impairments, however, depends on a careful analysis of the cognitive procedures that are instrumental to successful performance. Consider a series of experiments by Ellis at al. (1997) on the effects of "depressed" mood inductions on the detection of contradictions in text.

Ellis et al. found that students who had received the "depressing" version of a mood-induction procedure detected fewer contradictions than did those in the neutral condition, even after the students had been alerted to the possible presence of contradictions. The authors saw the warning about possible contradictions as a focusing manipulation and interpreted the mood effect for participants so warned as evidence counter to an initiative account. Although the search for boundary conditions on the account is important, the justification for Ellis et al.'s interpretation is questionable. First, the experimental induction of depressed mood does not always serve as a reasonable model for naturally occurring depressed or dysphoric mood states (see Hertel \& Rude, 1991b; Parrott \& Hertel, 1999). Second, the instructions to search for contradictions was given right after the "depressed" participants-and not those in the neutral condition-had been encouraged to entertain any thoughts that came to mind as part of their induction procedure. Differential carry-over effects of distraction possibly interfered with the control intended by the warning. The third point is the more general point about the adequacy of experimental control.

Consider that evidence for remediation of dysphoria- or depressionrelated impairments has been based on manipulations that guided participants' processing quite specifically. For example, Hertel and Hardin (1990) inferred that nondysphoric participants' stochastic dependence of homophone recognition on prior spelling reflected the use of an attentional strategy at the time of the test; we therefore guided the dysphoric participants' use of that strategy, trial-by-trial, and remediated the recognition deficit. Hertel and Rude (1991a,b) surmised that the constraints on attention 
during initial exposure to target materials were lax; we therefore tightened the demands of the orienting task by requiring sustained attention to the targets and thereby remediated the deficit in subsequent recall. In contrast, the pretask instructions given by Ellis et al. (1997) might not have served the purpose of guiding participants to engage in beneficial procedures during the task itself. In short, "depression-induced" participants were encouraged to let their minds wander, and attention was not focused by specific response requirements as the task proceeded. The cognitiveinitiative account-or any other account that stresses the attention-directing aspects of task requirements-cannot be ruled out on the basis of the failure to focus attention sufficiently.

Understanding the specific procedures that contribute to successful task performance is, of course, a very general goal in cognitive psychology. The point of studying effects of mood or relationships to clinical syndromes is not only to achieve an understanding of the state or syndrome, but also to determine whether our theoretical frameworks can accomodate emotionrelated phenomena. There is little reason to believe that these goals should be easily achieved, given the difficulty of understanding the level of procedural specificity that underlies task performance (see Kolers \& Roediger, 1984). Thus far, my colleagues and $I$ have shown that deficiencies in deliberate memory associated with depressed and dysphoric states can be understood in terms of attentional control. We know that personal concerns can occupy attention and interfere with the use of procedures that would otherwise be self-initiated. Truly successful remediation of impairments, through guiding the use of beneficial procedures, has been achieved in only two experimental paradigms: one that focused attention sufficiently during initial exposure and one that directed the use of recognition strategies. Clear failures to gain experimental control have also been demonstrated. For example, Hertel and Milan (1994) demonstrated that dysphoriarelated impairments in the controlled component of recognition memory could not be remediated simply by reinstating contextual cues at the time of testing. However, the discovery that a particular attention-focusing procedure is inadequate should not discourage the search for better means.

In general, investigators of depression-related impairments must move beyond the mere assertion that attention is diverted by personal concerns to an understanding of the specific procedures involved in producing and remediating the impairments. A proper understanding of a phenomenon can be shown by its experimental reduction or elimination. To do that in the case of cognitive impairments in depression, we need to know the nature of the "something" that someone has done without being told.

\section{REFERENCES}

Abramson, L. Y. Metalsky, G. I., \& Alloy, L. B. (1989). Hopelessness depression: A theorybased subtype of depression. Psychological Review, 96, 358-372.

Beck, A. T., Rush, A. J., Shaw, B. F., \& Emery, G. (1979). Cognitive therapy of depression. New York: Guilford.

Beck, A. T., Ward, C., Mendelson, M., Mock, J., \& Erbaugh, J. (1961). An inventory for measuring depression. Archives of General Psychiatry, 4, 561-571.

Buchner, A., Erdfelder, E., \& Vaterrodt-Plünnecke, B. (1995). Toward unbiased measurement of conscious and unconscious memory processes within the process dissociation paradigm. Journal of Experimental Psychology: General, 124, 137-160.

Craik, F. I. M. (1986). A functional account of age differences in memory. In F. Klix \& H. Hagendorg (Eds.), Human memory and cognitive capabilities: Mechanisms and performances (pp. 409-422), Amsterdam: Elsevier.

Danion, J.-M., Willard-Schroeder, D., Zimmermann, M.-A., Grange, D., Schilenger, J.-L., \& Singer, L. (1991). Explicit memory and repetition priming in depression. Archives of General Psychiatry, 48, 707-711.

Denny, E. B., \& Hunt, R. R. (1992). Affective valence and memory in depression: Dissociation of recall and fragment completion. Journal of Abnormal Psychology, 101, 575-580.

Einstein, G. O., \& McDaniel, M. A. (1990). Normal aging and prospective memory. Journal of Experimental Psychology: Learning Memory, and Cognition, 16, 717-726.

Ellis, H. C., \& Ashbrook, P. W. (1988). Resource allocation model of the effects of depressed mood states on memory. In K. Fiedler \& J. Forgas (Eds.), Affect, cognition and social behavior (pp. 25-43). Toronto: Hogrefe.

Ellis, H. C., Thomas, R. L., \& Rodriguez, I. A. (1984). Emotional mood states and memory: Elaborative encoding, semantic processing, and cognitive effort. Journal of Experimental Psychology: Learning, Memory, and Cognition, 10, 470-482.

Ellis, H. C., Ottoway, S. A., Varner, L. J., Becker, A. S., \& Moore, B. A. (1997). Emotion, motivation, and text comprehension: The detection of contradictions in passages. Journal of Experimental Psychology: General, 126, 131-146.

Gotlib, I. H., Roberts, J. E. \& Gilboa, E. (1996). Cognitive interference in depression. In I. G. Sarason, G. R. Pierce, \& B. R. Sarason (Eds.), Cognitive interference: Theories, methods, and findings (pp. 347-377). Mahwah, NJ: Erlbaum.

Hartlage, S., Alloy, L. B., Vazquez, C., \& Dykman, B. (1993). Automatic and effortful processing in depression. Psychological Bulletin, 113, 247-278.

Hasher, L., \& Zacks, R. T. (1979). Automatic and effortful processes in memory. Journal of Experimental Psychology: General, 108, 356-388.

Henriques, J. B., \& Davidson, R. J. (1991). Left frontal hypoactivation in depression. Journal of Abnormal Psychology, 100, 535-545.

Hertel, P. T. (1994). Depressive deficits in word identification and recall. Cognition and Emotion. 8, 313-327.

Hertel, P. T. (1997). On the contribution of deficient cognitive control to memory impairment in depression. Cognition and Emotion, 11, 569-583.

Hertel, P. T. (1998). The relationship between rumination and impaired memory in dysphoric moods. Journal of Abnormal Psychology, 107, 166-172.

Hertel, P. T., \& Hardin, T. S. (1990). Remembering with and without awareness in a depressed mood: Evidence of deficits in initiative. Journal of Experimental Psychology: General, 119, 45-59.

Hertel, P. T., \& Knoedler, A. J. (1996). Solving problems by analogy: The benefits and detriments of hints and depressed moods. Memory \& Cognition, 24, 16-25. 
Hertel, P., \& Meiser, T. (in press). Capacity and procedural accounts of impaired memory in depression. In U. von Hecker, S. Dutke, \& G. Sedek (Eds.), Generative thought and psychological adaptation: New perspectives on cognitive resources and control functions. Dordrecht, The Netherlands. Kluewer Press.

Hertel, P. T., \& Milan, S. (1994). Depressive deficits in recognition: Dissociation of recollection and familiarity. Journal of Abnormal Psychology, 103; 736-742.

Hertel, P. T., \& Rude, S. S. (1991a). Depressive deficits in memory: Focusing attention improves subsequent recall. Journal of Experimental Psychology: General, 120, 301-309.

Hertel, P. T., \& Rude, S. S. (1991b). Recalling in a state of natural or induced depression. Cognitive Therapy and Research, 15, 103-127.

Jacoby, L. L. (1991). A process dissociation framework: Separating automatic from intentional uses of memory. Journal of Memory and Language, 30, 513-541.

Jacoby, L. L. (1996). Dissociating automatic and consciously controlled effects of study/test compatibility. Journal of Memory and Language, 35, 32-52.

Jacoby, L. L., Kelley, C. M., \& Dywan, J. (1989). Memory attributions. In H. L. Roediger III \& F. I. M. Craik (Eds.), Varieties of memory and consciousness (pp. 391-422), Hillsdale, NJ: Erlbaum.

Jennings, J. M., \& Jacoby, L. L. (1993). Automatic versus intentional uses of memory: Aging, attention and control. Psychology and Aging, 8, 283-293.

Johnson, M. H., \& Magaro, P. A. (1987). Effects of mood and severity on memory processes in depression and mania. Psychological Bulletin, 101, 28-40.

Kolers, P. A., \& Roediger, H. L. III (1984). Procedures of mind. Journal of Verbal Learning and Verbal Behavior, 23, 425-449.

Logan, G. D., \& Etherton, J. L. (1994). What is learned during automatization? The role of attention in constructing an instance. Journal of Experimental Psychology: Learning, Memory, and Cognition, 20, 1022-1050.

Morris, C. D., Bransford, J. P., \& Franks, J. J. (1977). Levels of processing versus transferappropriate processing. Journal of Verbal Learning and Verbal Behavior, 16, 519-533.

Needham D. R., \& Begg, I. M. (1991). Problem-oriented training promotes spontaneous analogical transfer: Memory-oriented training promotes memory for training. Memory \& Cognition, 19, 543-557.

Nolen-Hoeksema, S., \& Morrow, S. (1993). The effects of rumination and distraction on naturally occurring depressed moods. Cognition and Emotion, 7, 561-570.

Parrott, W. G., \& Hertel, P. T. (1999). Research methods in cognition and emotion. In T. Dalgleish \& M. Power (Eds.), The handbook of cognition and emotion. (pp. 61-81). Chichester: Wiley.

Rude, S. S., \& Hertel, P. T. (1987, November). Remembering as a consequence of cognitive effort and depression. Paper presented at the meeting of the Association for the Advancement of Behavior Therapy, Boston.

Rude, S. S., Hertel, P. T., Jarrold, W., Covich, J., \& Hedlund, S. (1999). Depression related impairments in prospective memory, Cognition and Emotion, 13, 267-276.

Simon, H. A. (1994). The bottleneck of attention: Connecting thought with motivation. In W. D. Spaulding (Ed.), Integrative views of motivation, cognition, and emotion: Nebraska symposium on motivation (Vol. 41, pp. 1-21), Lincoln: University of Nebraska Press.

Tyler, S. W., Hertel, P. T., McCallum, M. C., \& Ellis, H. C. (1979). Cognitive effort and memory. Journal of Experimental Psychology: Human Learning and Memory, 5, 607-617.

Watkins, P. C., Mathews, A., Williamson, D. A., \& Fuller, R. D. (1992). Mood-congruent memory in depression: Emotional priming or elaboration? Journal of Abnormal Psychology, 101, 581-586.
Watkins, P. C., Vache, K., Verney, S. P., Muller, S., \& Mathews, A. (1996). Unconscious mood-congruent memory bias in depression. Journal of Abnormal Psychology, 105, 34-41 (1981). Cognitive Weingartner, H., Cohen, R. M., Murphy, D. L., Martello, J., \& Geral
processes in depression. Archives of General Psychiatry, 38, 42-47.

Williams, J. M. G., Watts, F. N., MacLeod, C., \& Mathews, A. (1988). Cognitive psychology and emotional disorders. New York: Wiley.

Williars, J. M. G., Watts, F. N., MacLeod, C., \& Mathews, A. (1997). Cognitive psychology and emotional disorders (Second Edition). New York: Wiley. 